\title{
Conservation and Perpetuation of the Art of Dance for Worshipping Phra That in the Isan Region
}

\author{
Saowarut Thotsa ${ }^{1}$, Urarom Jantamala ${ }^{2}$ \& Patamawadee Chansuwan ${ }^{2}$ \\ ${ }^{1}$ The Faculty of Cultural Science, Mahasarakham University, Khamriang Sub-District, Kantarawichai District, \\ Maha Sarakham Province, Thailand \\ ${ }^{2}$ Faculty of Fine Arts, Mahasarakham University, Mahasarakham Province, Thailand \\ Correspondence: Saowarut Thotsa, Mahasarakham City Foundation School, Mueng District, Maha Sarakham \\ Province, 44000, Thailand. E-mail: saowarut_288@hotmail.com
}

Received: March 24, 2013 Accepted: April 18, 2013 Online Published: June 29, 2013

doi:10.5539/ass.v9n9p219 URL: http://dx.doi.org/10.5539/ass.v9n9p219

\begin{abstract}
The sacred chedi of northeastern Thailand are important centres of cultural and spiritual heritage. Once every year, the local communities gather together at holy ceremonies and perform dances to worship and respect the hallowed buildings and their surrounding areas. It is a quirk of modernity that the adaptations being made to harmonize the dances with current society are the very changes that are killing them. This research considers the background and current conditions of worship dances in northeastern Thailand to suggest a model for their future conservation. The investigation ultimately shows how cultural diffusion can ensure the continued existence of this priceless art form.
\end{abstract}

Keywords: the art of Thai dance, conservation, inheritance, worship, chedi, Isan region

\section{Introduction}

Dance is important for all people. His Royal Highness Prince Damrong Rajanubhab wrote that dance is a custom found in all nations in all languages and cannot be accredited to a specific place. Nevertheless, the methods of dance are specific to nations, although it must not be said that dance is merely a feature of human civilization, as animals can also dance. This is clearly visible in dogs, chickens and crows. When the mood is fitting, these animals dance, jump, strut and move their bodies in a number of different postures specific to their species. Philosophers researching data about dance have come to the agreement that dance has roots in the behavior of animals. When one sensation is felt as emotion, every other sensation will follow. If the emotion is strong and the individual does not suppress that emotion, it will be visible in an action. One example of this is a newborn baby. If the baby is in a good mood, it will dance and appear happy. If the baby is in a bad mood, it will cry and scream. The expressions of these positive and negative sensations of feeling are built until the procedure of dance is reached (Watcharasukum, 1987, p. 1).

Dance in northeastern Thailand is a part of ancient local culture that has two foundations. The first foundation is ceremonial dance, such as the Phi Fa Spirit Dance and the Rocket Dance Ceremony. The Phi Fa Spirit Dance is a dance to invite the Phi Fa spirit into the bodies of the dancers. The dance has characteristics similar to a comatose state, where dancers are half asleep, half awake. The Rocket Dance is a dance to ask for rain from the spirits but the emphasis is upon enjoyment and merriment. The postures in the Phi Fa Spirit Dance are from prehistoric communities, who used them to communicate with sacred relics. The Rocket Dance is a customary procession with defined postures and organized arrangement to make the dance beautiful and pleasing to the eye. This style is likely an evolution of the Phi Fa Spirit Dance. The second foundation is in Mor Lam (folk music) productions across northeastern Thailand. Investigation of the evolution of Mor Lam Phuen (a recital of local legends), Mor Lam Klon (a vocal 'fight'), Mor Lam Mu (folk opera), Mor Lam Phloen (a group narrative) and Adapted Mor Lam found that there has been an increased variety of dance postures and styles used in these productions over time, especially regarding the bodies of the dancers. In recent years, dance in Mor Lam productions has been influenced from backing dancers and bands in Thai country music, such as collective dance compositions and dances popularized by celebrities (Samlipan, 1997, p. 35-36).

The dance postures of northeastern people are natural. Their style of gesture is non-defined and they move their 
bodies and hands in a fashion similar to the grace of an insect. The jeeb is the hand position of Thai dance in which the tips of the thumb and index fingers touch to a point. In Isan dance, the jeeb has no strict style and often the fingertips do not touch. In the central region of Thailand there are a number of jeeb positions, each with different meanings, determined by the placement of the hands. In northeastern dance it is impossible to identify these positions due to the free form of the dance and, thus, the positions of the central dances cannot be replicated in northeastern dance (Wongprasert, 1989, p. 91).

The northeastern region of Thailand, or Isan, has successfully progressed over a long time. It is a place where the inheritance of customs and culture has a high value, regardless of whether it is language, food, art or handicrafts. Aside from these aspects, there are ancient ruins and ancient chedi, or Thai Buddhist stupas, which can reveal the prosperity and national legends of the past (Tammawat, 1985, p. 15).

Chedis in Isan are places that people in the local community worship, pray to and respect. When people have beliefs and respect in the same things, it creates mutual appreciation. This allows for mental communication that generates good results in other activities, such as religious ceremonies. Even further, the combination of culture and religion at ceremonies and dances to worship chedis has been transformed into an annual community activity. The chedis of Isan are cultural locations where art and artistic performances can be seen during times of worship; they are tourist attractions for the provinces and places to study cultural knowledge.

The art of dance has been used for centuries as a medium to worship these chedis at religious ceremonies, which signifies the importance of the buildings. To try and continue the tradition of worship dance in modern society, adaptations and improvements have been made to the components of the dance. These ensure that the identity of the dance is correctly adapted to the present day to harmonize with current conditions and draw interest from tourists. However, these alterations have caused the traditional identity of local dance and its components to decline. The researchers were thus interested in a conservation method to maintain the art of worship dance in its original form, including a way to pass on the style of dance, postures, costumes and music as a part of local identity. This is to be achieved while ensuring that the dances are popular tourist attractions and sources of cultural knowledge, which will have the additional result of boosting the local economy in the future.

\section{Research Aims}

This research has three research aims: a) to study the historical background of the art of dance to worship chedis in northeastern Thailand; b) to study the current conditions of and problems with conservation and inheritance of dance to worship chedis in northeastern Thailand; c) to study a method of conservation and inheritance for dance to worship chedis in northeastern Thailand.

\section{Research Methodology}

The study area for this research included the three provinces of Nakhon Phanom, Maha Sarakham and Sakon Nakhon in northeastern Thailand. The three chedis of Phra That Phanom, Nakhon Phanom Province, Phra That Na Dun, Maha Sarakham Province, and Phra That Choeng Chum, Sakon Nakhon Province were specifically chosen for the research. The research population was selected from the Phu Thai Renu Nakhon Performance to Phra That Phanom, Renu Nakhon District, Nakhon Phanom Province, the Rabam Jampasri Performance to Phra That Na Dun, Na Dun District, Mahasarakham Province, and the Phu Thai Sakon Ban Non Hom Performance to Phra That Choeng Chum, City District, Sakon Nakhon Province. The number of informants totaled one hundred and seventeen people, comprised of thirty key informants, fifty-four casual informants and thirty-three general informants. The tools used for data collection were participant and non-participant observation, structured and non-structured interview and focus-group discussion. Data validation was conducted using a triangulation method. The research results are here presented as a descriptive analysis.

\section{Results and Discussion}

\subsection{The Historical Background of the Art of Dance to Worship Chedis in Northeastern Thailand}

Chedis, or Thai Buddhist stupas, were constructed to enshrine Sarira (Buddhist relics), buddhahood (the state of perfect enlightenment) or Arhat (a 'perfected one'). They were built large and tall, so to look important. They were built from brick, holding handcrafted stucco patterns and revered to the same extent as prasat (temples) in the glorious religion of Buddhism. The spire of the chedi is the most striking feature of the structure and can be created in a variety of different styles, such as a square lotus shape (most commonly used), an octagonal shape, or an overturned bell shape. That, the Thai name for the chedi, means 'those and that which are kept' and roughly translates into English as 'realm'. The word implies that all objects in the world, both real and abstract, will not disappear, although they may change form or colour; they do not need to be proven. Buddhist doctrine uses the word that frequently, such as in lokathat (Earthly realm), nipanthat (Nirvana; God realm), gammathat 
(Desire realm), rubthat (Form realm), and Arubthat (Formless Realm) (Encyclopedia of Thai Culture, 1995, pp. 135-140).

Legends of chedis that have been inherited over time from ancestors to descendents are legends that delve deep into the beliefs of the people. These beliefs are revealed in the local ceremonies and customs, which are both holy and trusted. When people desire merit or success, they will pay respect, worship and ask for blessings. This lifestyle has been passed down over time. Holy places that people respect and worship are centres of communal trust in each area of Isan and are often in the form of ancient chedis. Chedis are important for Buddhism and all people who respect them, so ceremonies of worship are held. Examples of chedis in Isan are Phra That Phanom, Nakhon Phanom Province, Phra That Na Dun, Maha Sarakham Province, and Phra That Choeng Chum, Sakon Nakhon Province. These three chedis hold ceremonies or events of worship every year, which are beautiful examples of Buddhist customs that have survived over time. The chedis remain places of important cultural value in the locality and hold worship dance ceremonies each year as part of their identity. The customs of worship dance in these three chedis respect the venerable and sacred ground on which they are held. They are also forms of worship to offer edible items to the chedi on important Buddhist religious days. All members of the population will come to receive a blessing as a form of good luck and prosperity for themselves. This is a custom that has been passed on for a long time and has been assimilated into modern life.

Phra That Phanom, Nakhon Phanom Province is sacred ground that is widely respected. For a conscious life, one must pay respect and ask for blessings from the chedi so to achieve prosperity. According to legend, the worship dance of Phra That Phanom has been performed ever since the chedi's construction. Phra That Phanom is an ancient chedi that is worshipped and used as a center of consciousness for people both sides of the Mekong River. There is an annual event held at the end of Buddhist Lent between the twelfth day of the waxing moon in the eleventh month of the Thai lunar calendar and the first day of the waning moon in the twelfth month. The costumes used for the dances will be adapted from the most striking aspects of Nakhon Phanom identity and the dance will be holy or auspicious in dedication to Phra That Phanom. This event acts as a blessing for audiences and tourists alike (Salipan, 2005, p. 2).

Phra That Na Dun, Maha Sarakham Province is a sacred site that Buddhists revere highly, particularly Maha Sarakham locals, who have adhered to their faith in Phra Na Dun as part of everyday life for many generations. Every year, during the third month of the Thai lunar calendar (Makha), the people of Na Dun District and Maha Sarakham Province will hold an event to worship Phra Tat Na Dun, so that the people may come and pay their respects, participate in holy ceremonies and congregate to reflect and meditate in front of Phra Tat Na Dun. This is a big event in Isan and on a national level, so believers in the Buddhist faith will travel from all corners to the chedi. The event is held every year in the Isan area on the fifteenth day of the waxing moon in the third month of the Thai lunar calendar (Mahka Bucha Day). This special ceremony is held at Phra That Na Dun for nine days and nine nights and allows people to participate in Buddhist activities, such as a parade or procession to showcase the customs of the twelve months, merit making services, the Makha Bucha candle procession, Vipassana meditation, a variety of exhibitions, colour, light and sound performances and worship dance performances reenacting the history of the ancient city of Nakhon Jampasri. These are all excellent examples of the inheritance of Buddhist and art culture (Tanamalpong, 1999, p. 15).

Phra That Choeng Chum, Sakon Nakhon Province is home to the imprints of the four holy footprints of Kakusandha Buddha, Konagamana Buddha, Kassapa Buddha and Gautama Buddha. It is believed that the Buddha came to preach to the monk Suwannapingkara at Pu Khao Nam Lod Choeng Chum so to increase the strength of his faith. This was an inspiring miracle, as three orbs of light emerged from the mouth of the Buddha, which, upon seeing, the monk took for a wonder of the Lord Buddha and stated his willing belief in Buddhism. The Lord Buddha thus declared the site a place of outstanding ideals, which is why the four Buddhas came to meet and left their footprints at Pu Khao Nam Lod Choeng Chum for humanity to worship. Following his new-found belief, Suwannapingkara removed his golden crown, placed it on the footprints and commissioned the creation of Phra That Choeng Chum to commemorate the meeting of the four Buddhas. At that time, Phra Nang Narai Jeng Weng Ratchatewi, a monk in the area, and his lady-in-waiting danced to worship the Buddhas. From these origins the dance is performed every year from the eleventh to the fifteenth days of the second month of the Thai lunar calendar.

\subsection{The Current Conditions of and Problems with Conservation and Inheritance of Dance to Worship Chedis in Northeastern Thailand}

In this study, the characteristics of the dance postures performed during the ceremonies were taken into consideration and revealed the local artistic identity. It is a simple art, yet vigorous and energetic. Despite the 
lack of real order, it is beautiful. There are many different types of posture, which differ by area and performer. These include Phu-Thai dance, Kranob-Tingtong, Reum Anre and dance used in Mor Lam, especially Mor Lam Klon. These are fun dances for the performers and thus entertain the audiences, particularly the postures of Mor Lam Klon, which are called giaow postures. Isan people like these dances very much (Tammawat, 1985).

Isan art is in the form of music and dance, which relate to the local lifestyle. There are many dance gestures, slow, fast and reserved (Wongprasert, 1989, p. 4). There are eight major categories of Isan dance: a) dance imitating the style of animals; b) dance following ancient methods; c) dance to a melody; d) tribal dance; e) dance from literature; f) art and craft dance; g) dance for entertainment; h) ceremonial dance, dance for worship.

The lifestyle of Isan people is related to the dances inherited from ceremonies, as Isan people adhere to superstitions of spirits and the soul. This means that the majority of ceremonies are aimed at connecting with the soul via a shaman or medium. There will also be an offering for the spirit or soul, while the shaman must recite a magical chant to communicate with the spirit in order to plea with the spirit to go away. These chants have been developed and adapted as songs at ceremonies. The descriptions in the songs are gradual, which means that music or dance is able to be used to help the procedure, such as in the Phi Fa Spirit Dance in the treatment of the sick.

There is a variety of art used in culture and customs in each area, in each province. Art and culture reveal the beliefs, customs, religion, lifestyle and occupations of local people. It can be clearly seen that the Isan region is a territory that is home to a range of cultures that have different features in each location and are unlike other region of Thailand, particularly cultures relating to lifestyle and religion. For this reason it is possible to observe a beautiful cultural form in Isan that has been exceptionally well inherited over time.

Every year there will be customs or ceremonies to worship the three chedis researched in this study, which are beautiful examples of Buddhist culture in Thailand that has been practiced for a long time. Chedis are important in Buddhism as all people worship them and there are many sacred ceremonies to respect them. Additionally, the chedis host ceremonial dance performances, which are important for local culture and are part of the identity of the annual events. The worship dances in these three chedis are dances to the sacred sites and are to celebrate the chedis on important Buddhist days. All people will come to ask for blessings and pay respects in order to find prosperity for themselves. This is a custom that has been passed on for many centuries until the present.

Worship dances in each of the three provinces studied are dances to pay respect to sacred relics that are revered by people in the local area. The worship dances are held just once a year in order to show deference to the chedis, which creates problems for conservation and inheritance. Currently, improvements or adaptations are made to modernize the dances in line with popular trends, which neglect the original form of the art. Changes are made to the style of the dance and music is mixed with modern genres, which causes the original music to disappear. Some productions alter their costumes to be more in line with modern fashion, which make the shows look strangely elaborate. These changes cause the identity and art of Isan people to decline. For this reason it is necessary to conserve the methods for the future and improve the current situation so that future generations are able to inherit knowledge of the custom.

\subsection{A Method of Conservation and Inheritance for Dance to Worship Chedis in Northeastern Thailand}

Following analysis of the problems with conservation and inheritance of worship dance in Isan, the researchers determined an alternative method of preservation. This is to be achieved by transmission, promotion and publicity of the dances to worship chedi through cultural diffusion. The concept of cultural diffusion can be contrasted with independent invention, which may happen in many places at the same time. Independent invention leads to cultural appropriation which would see a continuation of the kinds of problems currently faced by worship dance inheritance in northeastern Thailand. Fritz Graebner and Wilhelm Schmidt saw culture as diffusing from a centre or origin into the immediate surrounding societies. Culture may be diffused into every society in response to the needs of the people. Cultural diffusion is not restricted, unless there are geographical obstacles preventing human contact. This theory was called the kulturkreis and is the precise model that any conservation of worship dance in Isan chedis should follow (Wannasiri, 1997, p. 99-101).

Cultural diffusion originates from a number of factors. The first are geographical factors. There must be no geographical obstacles as these will prevent humans from passing their cultures to different geographical areas. The second are economic factors that come from poverty, lack of self-sufficiency and lack of supplies. These mean that people must search for new means of economic sustenance. The third are social factors that alter the way of life, behavior and knowledge and come from study of a culture, inter-cultural marriage or immigration. The fourth are communication factors that aid cultural diffusion, because roads or other communication methods link cultures so that they can be diffused quickly (Wannasiri, 1997, p. 93). Cultural diffusion is a factor that 
causes the lifestyle of humans to change. Human existence in families and societies, with communication and trade, causes the absorption of all contacted cultures, which causes diffusion and transmission from one society to another. This is concerned with the research of G. Elliot Smith, William J. Perry and W.H.R. Rivers (Santasombat, 1997, p. 25), who considered Egypt as the cradle of civilization and the first culture to diffuse knowledge, art and science throughout the world via trade. The theories of Graebner and Schmidt, as well as those of Smith, Perry and Rivers suggest that the majority of people do not commonly create their own ideas and do not invent. Instead they use the ideas of others: cultural appropriation. It is the conclusion of these researchers that worship dance to chedis in northeastern Thailand should not be reinvented in a new cultural form, but continued and preserved for the cultural treasure that it is, via methods of transmission, promotion and publicity.

The method of conservation and transmission in order to inherit and maintain dance to worship chedis in northeastern Thailand so that it does not decline and disappear should be supported by governmental and private institutions, both domestically and internationally. This will accelerate the promotion of the strategic policies and plans of conservation. The results of the research are consistent with the theory of Yongtanit Pimonsatien (2000, p. 1), which concluded that cities with no past spirit, have little hope of for the future. Cities can be compared to people in that the heritage of the past helps in creating new identities and development opportunities. People who are unable to learn from the past or those with no realization of the value of antiquity are those people who cannot invent. Worship dance conservation must not neglect its own heritage.

The results of this research show a method of conservation and inheritance of the art of dances to worship chedi so that they are improved, maintained and promoted as part of the local culture for future generations to study.

\section{References}

Anon. (1995). 'Chedis'. In Encyclopedia of Thai Culture: Isan Region. Bangkok: Siam Commercial Bank.

Pimonsatien, Y. (2000). Old Phuket Town Trail. Phuket: Phuket Municipal Office.

Salipan, N. (2005). Development of Worship Dance in Phra That Phanom. Bangkok: Chulalongkorn University.

Samlipan, S. (1997). Local Dance Postures in Isan: A case study of Roi-Et dance. Mahasarakham: Mahasarakham University.

Santasombat, Y. (1997). Humans and Culture. Bangkok: Thammasat University.

Tammawat, J. (1985). Research of Mor Lam Choreography in Isan Society in the Middle of the Century. Maha Sarakham: Srinakharinwirot University.

Tanamalapong, S. (1999). Ceremonies of Phra That Na Dun, Na Dun District, Maha Sarakham Province. Maha Sarakham: Mahasarakham University.

Wannasiri, N. (1997). Humanity, Society and Culture. Bangkok, Thammasat University.

Watcharasakum, S. (1987). Rong-Ngeng: Local Dancing of the South. Bangkok: Living.

Wongprasert, C. (1989). The Art of Isan Dance. Mahasarakham: Srinakharinwirot University.

\section{Copyrights}

Copyright for this article is retained by the author(s), with first publication rights granted to the journal.

This is an open-access article distributed under the terms and conditions of the Creative Commons Attribution license (http://creativecommons.org/licenses/by/3.0/). 